\title{
A survey on gross pathologic lesions on bovine livers and kidneys from a Halal abattoir in Cotabato City, Philippines
}

\author{
L.M. Bessitt ${ }^{1}$, V.D. Flores ${ }^{1,2}$, J.C.B. Tenorio ${ }^{1 *}$, V.B. Jimenez ${ }^{3}$, E.C. \\ Molina ${ }^{1}$, L.A. Lumbao ${ }^{1}$
}

\footnotetext{
${ }^{1}$ Department of Veterinary Paraclinical Sciences, ${ }^{2}$ Department of Veterinary Clinical Sciences, College of Veterinary Medicine, University of Southern Mindanao, Kabacan 9407, Cotabato, Philippines; ${ }^{3}$ Department of Veterinary Microbiology, Parasitology, Pathology and Public Health, College of Veterinary Medicine, Central Mindanao University, Maramag, Bukidnon, Philippines

* Corresponding author: Email: jcbtenorio@usm.edu.ph ; Tel: (064) 572 2384;
}

Journal of Livestock Science (ISSN online 2277-6214) 13: 88-95

Received on 19/12/21; Accepted on 13/2/22; Published on 22/2/22

doi. 10.33259/JLivestSci.2022.88-95

\begin{abstract}
Postmortem examination of food animals during slaughter enables the identification of illnesses and health issues that subvert the quality of carcasses and offal. Gross pathological lesions seen at slaughter have important economic impact and implications on the Halal wholesomeness of these food items, and therefore there is a need to identify them. The study identified and described the gross pathological lesions found on the livers and kidneys of cattle slaughtered in a Halal abattoir in Cotabato City, Philippines from December 12, 2020 to January 28, 2021. A total of seventy (70) cattle were included in the study: 70 livers and 140 kidneys were collected and examined. The lesions identified in the bovine livers included fibrosis (15.71\%), cholangitis $(15.71 \%)$, liver fluke migratory tracts $(1.43 \%)$, and cirrhosis $(2.9 \%)$. Among the kidneys examined, white spotted kidneys $(10.71 \%)$, renal infarcts $(10.71 \%)$, renal atrophy $(6.43 \%)$, amyloidosis $(5.71 \%)$, ecchymosis $(4.29 \%)$, myoglobinuria $(2.86 \%)$, hydronephrosis $(2.86 \%)$, pyelonephritis $(2.14 \%)$ and renal cyst $(1.43 \%)$ were the lesions seen. Numerous gross pathological lesions were identified among the livers and kidneys assessed in the current study. Production and health management practices must be improved if the occurrence of these economically important pathological lesions is to be reduced.
\end{abstract}

Key words: Food safety; Gross pathologic lesions; Philippines; Postmortem inspection; Beef cattle 


\section{Introduction}

Meat inspection is a good source of data that can be used in epidemiological studies and for the practice of preventive veterinary medicine. Economically important animal diseases that persist in an area can be identified and recorded through the pathological lesions found in slaughter, thus postmortem inspection is important in disease control programs (Ahmad and Elsharawy, 2018; Ghalandarzadeh and Amniattalab, 2019). Moreover, postmortem inspection enables the production of wholesome meat products that are free from zoonotic risks (Ahmed et al., 2013; Jaja, et al., 2017). And more importantly, lesions in the meat and offal of beef render them unclean and unwholesome for human consumption, according to the tenets of Halal food preparation.

Pathologic lesions seen in cattle livers and kidneys are often the result of debilitating illnesses that may render the meat and offal of the animal unwholesome for human consumption. Diseases that affect the liver can change the morphological structure of the organ. Herenda et al. (2000) and Mohammed et al. (2012) showed that most condemnations of cattle livers were due to pathological findings such as fasciolosis, jaundice, hepatitis, hydatidosis, cirrhosis, melanosis, fatty liver, telangiectasis, and abscesses. Lesions in the kidneys disrupt the animal's ability to excrete waste products resulting in conditions that may render livestock animals unfit as food sources. According to Ahmad and Elsharawy (2018), the most common lesions found in bovine kidneys during slaughter are renal cysts, hydronephrosis, pyelonephritis, white spotted kidneys and urolitiasis. In another study, renal cysts were the most common lesion found in cattle slaughtered at M'lang Cotabato abattoir (Tolentino, 2020).

To date, there is no published study that investigated the pathologic lesions seen in bovine kidneys and livers from Cotabato City. Thus, the purpose of this study was to identify the common gross pathological lesions in the liver and kidney of slaughtered cattle during postmortem examination. The general objective of this study was to identify the different macroscopic pathological lesions found in the kidneys and livers of cattle slaughtered in the abattoir of Cotabato City, Philippines.

\section{Materials and methods}

\section{Ethical Considerations}

The study did not require animal welfare clearance because animals included in the study were part of the daily slaughter in the Cotabato City abattoir. The researchers did not have any role in the slaughter processing of the animals. The Cotabato City Slaughterhouse is a double A Halal abattoir; thus, its slaughtering procedures are compliant to national meat inspection and animal welfare regulations of the Philippines.

\section{Study Design}

A cross-sectional study was conducted to determine and describe the gross pathological lesions found on the liver and kidneys of slaughtered cattle in the abattoir of Cotabato City, Philippines $\left(7^{\circ} 11^{\prime} 30^{\prime \prime} \mathrm{N}\right.$, $\left.124^{\circ} 13^{\prime} 24^{\prime \prime E}\right)$. The abattoir slaughters about 5-20 beef cattle per day but it depends on the number of animals delivered and number of animals passing the antemortem inspection. All cattle that were slaughtered from December 12, 2020 to January 28, 2021 were enrolled in the study. A total of 70 slaughtered cattle were included: 70 livers and 140 kidneys were collected from these animals. Lesions found in the organs were recorded and documented via writing and taking photographs. Lesion identification was verified using the photographs by the fourth author who is a certified veterinary pathologist. The occurrence proportion of pathological lesion was then calculated using the data.

\section{Examination of the visceral organs}

The postmortem examination was done after the evisceration. Organs were then collected and examined by visual inspection, palpation, and systematic incision to observe pathological abnormalities (Meselle et al., 2012). Gross pathological lesions during the visual examination and palpation were recorded and identified. Incision was made at the surface of liver, and for further examination, it was continued at the base of the caudate lobe of the liver to examine the bile ducts (Collins and Huey, 2015). The two kidneys were enucleated and examined through visual examination, palpation, and incision for diagnosis (Collins and Huey, 2015). Visible lesions were evaluated and assessed whether they were superficial or extended deeply to the organ parenchyma. 


\section{Results}

Twenty-five (25) or $35.7 \%$ of the livers and 66 or $47.1 \%$ of the 140 kidneys examined in the study were found to have pathologic lesions. From the livers found to have gross pathologic lesions, 11 had fibrosis $(15.71 \%)$ and cholangitis $(15.71 \%)$, one had fluke migratory tracts $(1.43 \%)$, and two had cirrhotic lesions $(2.86 \%)$ (Figure 1). Meanwhile, nine pathologic conditions were identified in 66 kidneys out of the 140 samples evaluated (Figures 2 and 3). White spotted kidneys and renal infects were the most identified lesions at 15 each $(10.71 \%)$. Nine (9) kidneys (6.43\%) were affected by renal atrophy and only eight were found to have amyloidosis $(5.71 \%)$. Also, six kidneys had ecchymosis $(4.29 \%)$, myoglobinuria and hydronephrosis were found in four kidneys each $(2.86 \%)$, pyelonephritis was seen in three $(2.14 \%)$, and renal cysts were found in two kidneys $(1.43 \%)$.

Table 1. Gross pathological lesions on the livers and kidneys of slaughtered cattle in Cotabato City Halal Abattoir from December 12, 2020 to January 28, 2021.

\begin{tabular}{|c|l|c|c|c|c|}
\hline Organ & \multicolumn{1}{|c|}{ Lesion } & N & Positive & Negative & \% \\
\hline \multirow{5}{*}{ Liver } & Fibrosis & 70 & 11 & 59 & 15.71 \\
\cline { 2 - 6 } & Cholangitis & 70 & 11 & 59 & 15.71 \\
\cline { 2 - 6 } & Migratory tracts & 70 & 1 & 69 & 1.43 \\
\cline { 2 - 6 } & Cirrhosis & 70 & 2 & 68 & 2.86 \\
\cline { 2 - 6 } & TOTAL & 70 & 25 & 50 & 35.7 \\
\hline \multirow{5}{*}{ Kidney } & White spotted kidney & 140 & 15 & 125 & 10.71 \\
\cline { 2 - 6 } & Renal Infarcts & 140 & 15 & 125 & 10.71 \\
\cline { 2 - 6 } & Renal Atrophy & 140 & 9 & 131 & 6.43 \\
\cline { 2 - 6 } & Amyloidosis & 140 & 8 & 132 & 5.71 \\
\cline { 2 - 6 } & Ecchymosis & 140 & 6 & 134 & 4.29 \\
\cline { 2 - 6 } & Myoglobinuria & 140 & 4 & 136 & 2.86 \\
\cline { 2 - 6 } & Hydronephrosis & 140 & 4 & 136 & 2.86 \\
\cline { 2 - 6 } & Pyelonephritis & 140 & 3 & 137 & 2.14 \\
\cline { 2 - 6 } & Renal Cyst & 140 & 2 & 138 & 1.43 \\
\cline { 2 - 6 } & TOTAL & 140 & 66 & 74 & 47.1 \\
\hline
\end{tabular}

\section{Discussion}

Fasciolosis, as shown in Figures $1 \mathrm{~A}-1 \mathrm{~F}$, is a disease caused by liver flukes that may produce lesions that could affect the wholesomeness of affected bovine liver. Out of the 70 liver organs examined, 23 had visible lesions that include parenchymal fibrosis (Figures 1A-1E), enlargement and thickening of the bile duct walls due to fluke infection (Figures 1C-1E), white migratory tracks of the flukes at the liver surface (Figure 1D) and excretory pigment or hematin produced by the flukes as seen in Figure 1B. The occurrence of hepatic fasciolosis in present study was comparable to that observed by Tolentino (2019): $34.78 \%$ in an abattoir at Mlang, Cotabato, Philippines. Several abattoir studies conducted in South Ethiopia, Sokoto, Nigeria, El-Kharga, Egypt, and Ghana also reported that fasciolosis is a common finding in postmortem inspections (Addy et al., 2020; Elshraway and Mahmoud, 2017). Moreover, Dar et al. (2018) and Molina et al. (2008) described the gross pathology of bovine and bubaline livers infected with liver flukes; their descriptions were similar to those depicted in Figures 1A-1F. Fasciolosis is recognized as a zoonotic foodborne trematode infection that persist in the Philippines (Tenorio and Molina, 2021).

Cirrhosis is an end-stage liver pathology that often results from repeated insults on the organ caused by chronic illnesses (i.e., chronic fasciolosis). In both cirrhotic livers in the present study, visible lesions were identified to be parenchymal fibrosis (Figures $1 \mathrm{G}$ and $1 \mathrm{I}$ ), fibrin tags (Figure 1H), cholangitis (Figure 1J), and irregular liver shape (Figure 1H). A liver with cirrhosis is characterized by fibrosis and transformation of normal liver structure into abnormal nodules (Anthony et al., 1978). Parenchymal necrosis, regeneration, and diffuse fibrosis are known to result in the disorganization of the lobular structure in the entire liver (Anthony et al., 1978). It is also the final irreversible result of any severe hepatic disease (Ferrel, 2000). Cirrhotic bovine liver can be associated with fasciolosis (Machicad et al., 2016). 



Figure 1. Gross pathological lesions found in the livers examined in the study. Multifocal parenchymal fibrosis (A). Excretory pigment/hematin (B). Enlargement of the bile ducts (arrow) due to fluke infection (circle) (C). White migratory tracts due to liver flukes (D). Cut surface of the liver showing parenchymal fibrosis and thickened walls of the bile ducts (E). Multifocal parenchymal fibrosis with fibrin tags disseminated at liver surface (F). Locally extensive fibrosis (G). Fibrin tags with irregular liver shape (H). Focal cirrhosis (pinkish edge) (I). Enlargement of the bile ducts (cholangitis) (J). 

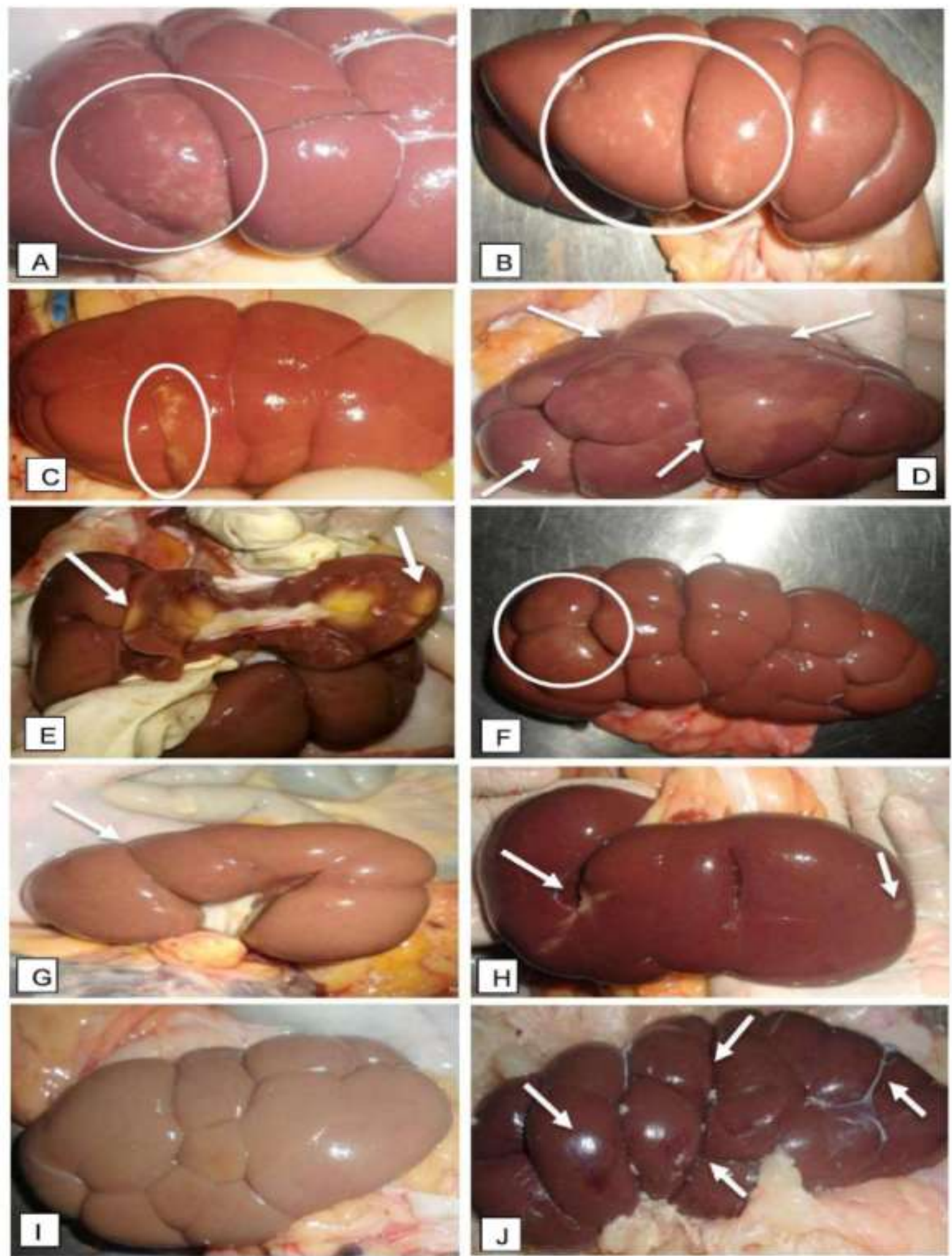

Figure 2. Gross pathological lesions found in the kidneys examined in the study. Multifocal white spots in $20 \%$ of the lobules suggestive of bacterial infection (A). Multifocal white spots suggestive of bacterial infection (B). Focal while spots (C). Multifocal renal infarcts (D). Cut surface of renal infarcts, pale discoloration of the parenchymal cortex $(E)$. Focal renal infarcts $(F)$. Renal atrophy $(G)$. Renal atrophy with focal renal infarct $(H)$. Amyloidosis (I). Multifocal ecchymosis (J). 

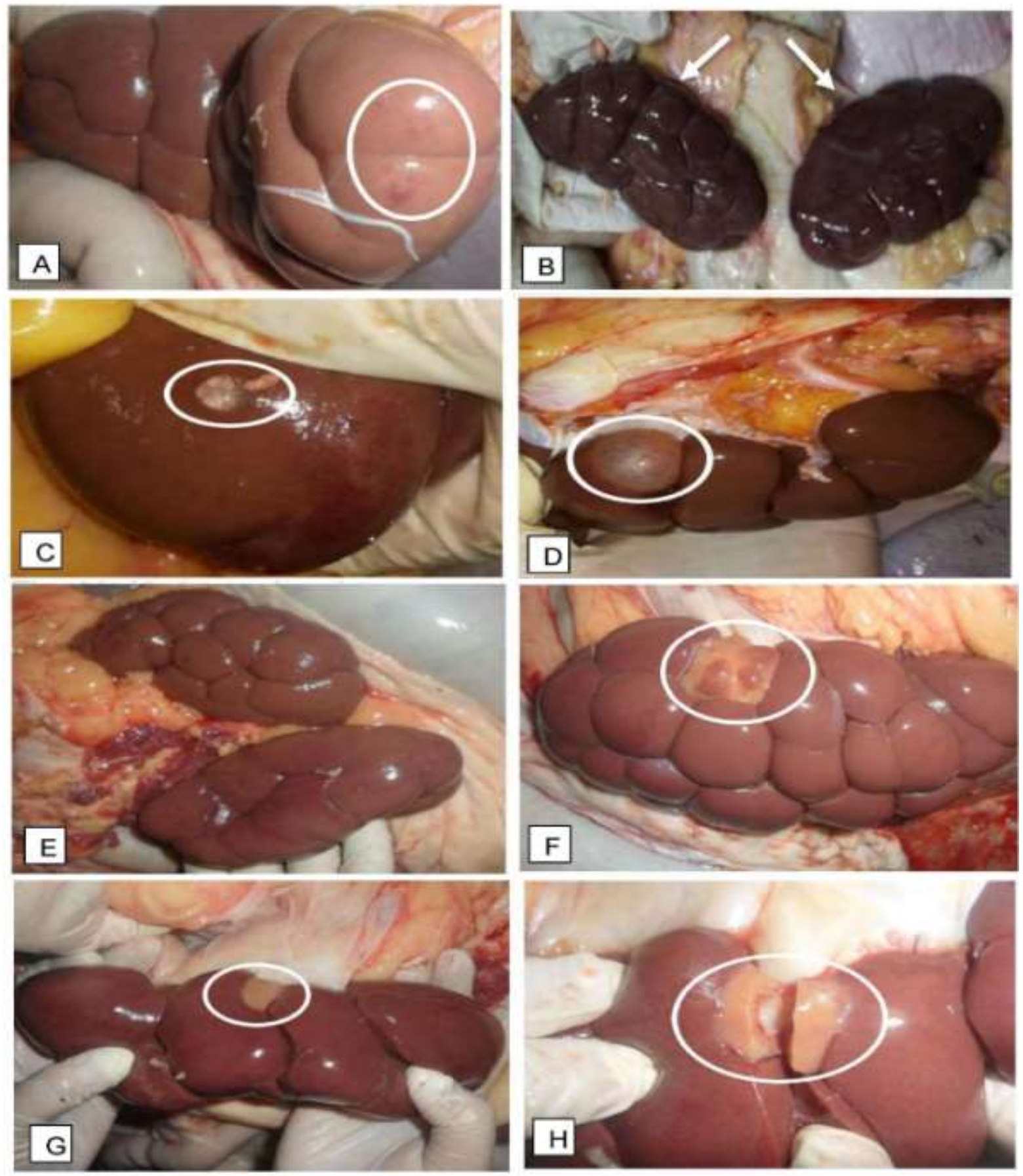

Figure 3. Other gross pathological lesions found in the kidneys examined in the study. Focal ecchymosis (A). Myoglobinuria (B). Hydronephrosis (C and D). Unilateral less lobulation as seen in pyelonephritis (E). Renal cyst $(\mathrm{F}$ and $\mathrm{H})$. Cut surface of renal cyst with fluid inside ( $\mathrm{G}$ and $\mathrm{I})$.

There were nine kidneys that showed renal atrophy. Renal atrophy, as shown in Figures $2 \mathrm{G}-2 \mathrm{H}$, is described as less in lobulation and size (Habib, 2018). The decrease in size may be due to inadequate or loss of nephronal circulation (Davran, et al., 2014; Habib, 2018). Renal atrophy can be secondary to renal diseases, acute pyelonephritis, and urinary tract obstruction (Davran et al., 2014).

Ecchymotic hemorrhages seen in six kidneys were multifocal (Figure 2J) and focal (Figure 3A). Extended time between stunning and sticking and erroneous method of stunning result in hemorrhages in organs of slaughter animals (Herenda et al., 2000). Further, electrical stunning may lead to ecchymotic hemorrhages or 
blood splashing due to the rapid increase of blood pressure induced by stimulation of the cardiac muscle and vasoconstriction (Herenda et al., 2000).

Pyelonephritis (Figure 3E) was observed as unilateral with less lobulation. Grossly, kidneys pyelonephritis apear swollen with lobulation that is less apparent when compared to a normal kidney, and the renal calyx and urethra are swollen with blood, mucus, and pus (Esmaeel, 2019). Moreover, pyelonephritis may be unilateral or bilateral and manifest catarrh and dilation of the renal pelvis, which is filled with slimy detritus, which may contain fibrinous clots or pus, and has a strong ammonia odor (Collins and Huey, 2015). Pyelonephritis is commonly caused by Corynebacterium renale and Escherichia coli (Esmaeel, 2019; Collins and Huey, 2015).

\section{Conclusion}

The present study provides baseline information for future monitoring of clean organs in a Halal abattoir. The presence of lesions in the edible organs may call for their condemnation, which may significantly affect meat traders economically. The Halal quality of meats and offal also decline due to the presence of lesions that are seen as sign of uncleanness and unwholesomeness in Islam. The results also highlight the need for proper management of livestock by raisers in order to avoid occurrence of infections.

It is recommended that subsequent histopathology examination and microbiological tests be done to definitely diagnose the gross pathologic lesions seen in the present study. Moreover, the city veterinary office should conduct information campaign regarding fasciolosis and intensify their efforts in controlling liver fluke infections in bovines and bubalines. Also, the bovine production and health management of farmers should be enhanced through community education geared towards maximizing production while ensuring the health of food animals.

\section{Acknowledgments}

This research did not receive funding from any institution. The researchers would like to acknowledge the personnel of the Cotabato City Halal Slaughterhouse and the City Veterinary Office for assisting them in the conduct of the study. The $1^{\text {st }}$ author would like to thank his family and friends who supported him in this research.

\section{Authors' contributions}

This research was part of the DVM thesis written and conducted by the $1^{\text {st }}$ author. The research was under the supervision of the $2^{\text {nd }}$ author. Drafting of the submitted article was done by the $3^{\text {rd }}$ author. Critical review and revisions were done by the $4^{\text {th }}, 5^{\text {th }}$, and $6^{\text {th }}$ authors. Verification of the identified lesions was provided by the $4 \mathrm{th}^{\text {th }}$ author who is an accredited Veterinary Pathologist. All the authors have read and approved the manuscript.

\section{Conflict of interest statement}

The authors have no conflict of interest to declare.

\section{References}

1) Addy, F., Gyan, K., Arhin, E., \& Wassermann, M. (2020). Prevalence of bovine fasciolosis from the Bolgatanga abattoir, Ghana. Scientific African, 8: 1-6. https://doi.org/10.1016/j.sciaf.2020.e00469

2) Ahmad, A.M, \& Elsharawy, N.T. (2018). Condemned meat and offal from different slaughtered animals at two different environments. Journal of Food: Microbiology, Safety and Hygiene, 3: 1-4. https://doi: 10.4172/2476-2059.1000133

3) Ahmed, A.M., Ismail, S.A.S., \& Dessouki, A.A. (2013). Pathological lesions survey and economic loss for male cattle slaughtered at Ismailia abattoir. International Food Research Journal, 20: 857-863.

4) Anthony, P.P., Ishak, K.G., Nayak, N.C., Poulsen, H.E., Scheuer, P.J., \& Sobin, L.H. (1978). The morphology of cirrhosis. Journal of Clinical Pathology, 31: 395-414.

5) Azizi, S., Tajbakhsh, E., Hajimirzaei, M.R., Gholami Varnamkhasti, M., Sadeghian, H., \& Oryan, A. (2012). Evaluation of "white-spotted kidneys" associated with leptospirosis by polymerase chain reaction based lipl32 gene in slaughtered cows. Journal of the South African Veterinary Association, 83:1-5.

6) Collins, D.S., \& Huey, R.J. (2015). Gracey's meat hygiene (11 ed.). The Atrium, Southern Gate, Chichester, West Sussex, PO19 8SQ, UK: John Wiley and Sons, Ltd.

7) Dar, J.S., Tak, I.U.R., Ganai, B.A., Shahardar, R.A., \& Gazanfar, K. (2018). Gross pathological and histopathological changes in the liver and bile duct of sheep with acute and chronic fasciolosis. International Journal of Advance Research in Science and Engineering, 7: 2031-2044.

8) Davran, R., Helvaci, \& M.R., Davarci, M. (2014). Left renal atrophy. International Journal Clinical and Experimental Medicine, 7: 1603-1606.

9) Elshraway, N.T., \& Mahmoud, W.G. (2017). Prevalence of fascioliasis (liver flukes) infection in cattle and buffaloes slaughtered at the municipal abattoir of El-Kharga, Egypt. Veterinary World, 10: 914-917. 
10) Esmaeel, S. (2019). Bovine pyelonephritis. Infectious and Epidemiological diseases, 1-5. http://uomosul.edu.iq/public/files/datafolder_2911/20191226_051525_710.pdf

11) Ferrel, L. (2000). Pathology: cirrhosis, hepatitis and primary liver tumors. update and diagnostic problems. Modern Pathology, 13: 679-704.

12) Ghalandarzadeh, B., \& Amniattalab, A. (2019). Prevalence and pathological evaluation of hepatic fatty change in cattle slaughtered at Urmia abattoir, northwest Iran. Iraqi Journal of Veterinary Sciences, 33: 45-50.

13) Habib, S. (2018). Kidney atrophy vs hypertrophy in diabetes: which cells are involved? Cell Cycle, 17, 1683-1687. DOI: 10.1080/15384101.2018.1496744

14) Herenda, D., Chambers, P.G., Ettriqui, A., Seneviratna, P., \& da Silva, T.J.P. (2000). Manual on meat inspection for developing countries. Rome, Italy: Food and Agriculture Organization of the United Nations, Rome. http://www.fao.org/3/t0756e/T0756E00.htm\#TOC

15) Jackman, B., \& Hathaway, S. (2012). Scientific evaluation of bovine post mortem examination procedures in new zealand. New Zealand: Science and Risk Assessment Directorate Standard Branch. https://www.fisheries.govt.nz/dmsdocument/4042/direct

16) Jaja, I.F., Mushonga, B., Green, E., \& Muchenje, V. (2017). A Quantitative Assessment of Causes of Bovine Liver Condemnation and Its Implication for Food Security in the Eastern Cape Province South Africa. Sustainability Journal, 9, 736. https://doi.org/10.3390/su9050736

17) Machicad, C., Machicado, J.D., Maco, V., Terashima, A., \& Marcos, L.A. (2016). Association of Fasciola hepatica infection with liver fibrosis, cirrhosis and cancer: a systematic review. Plos Neglected Tropical Disease, 10, e0004962. https://doi.org/10.1371/journal.pntd.0004962

18) Meselle, G., Guadu, T., Bogale, T., \& Chanie, M. (2012). Pathological Conditions Causing Organ and Carcass Condemnation andTheir Financial Losses in Cattle Slaughtered in Gondar, Northwest Ethiopia. African Journal of Basic and Applied Sciences, 4: 200-208.

19) Mohammed, N., Hailemariam, Z., \& Mindaye, S. (2012). Major cause of liver condemnation and associated financial Loss at Kombolcha elfora abattoir, South Wollo, Ethiopia. European Journal of Applied Sciences, 4, 140-145. https://doi:10.5829/idosi.ejas.2012.4.4.64235

20) Molina, E.C., Skerratt, L.F., \& Campbell, R. (2008). Pathology of fasciolosis in large ruminants. Aciar Monograph Series, 133: 94-98.

21) Mukherjee, S.R. (2014). Global Halal: meat, money, and religion. Religions, 5: 22-75.

22) Snyder, P. (2007). Diseases of immunity: amyloidosis. St.Lois, Mo, USA: Mosby Elsevier.

23) Taghipur-Bazargani, T., Khodakaram-Tafti, A., Ashrafi, I., \& Abbassi, A.M. (2015). Giant hydronephrosis and secondary pyelonephritis induced by Salmonella dublin in a Holstein calf. Iranian Journal of Veterinary Research, 16: 114-116.

24) Tenorio, J.C.B. and Molina, E.C. (2021). Monsters in our food: Foodborne trematodiasis in the Philippines and beyond . Veterinary Integrative Sciences, 19: 467-485.

25) Tolentino, H.G. (2020). Gross pathological lesions of the heart, lungs, liver and kidneys of slaughtered cattle in M'lang, Cotabato. Undergradute Thesis. University of Southern Mindanao, Kabacan, Cotabato, Philippines. 